\title{
Sexual well being of breast cancer patients
}

\author{
Milena Lachowicz' , Joanna Kufel-Grabowska2, ${ }^{3}$, Mikołaj Bartoszkiewicz ${ }^{4}$, Rodryg Ramlau ${ }^{5}$, \\ Krzysztof Łukaszuk ${ }^{6,7}$
}

\author{
${ }^{1}$ Department of Oncology and Radiotherapy, Medical University of Gdansk, Gdansk, Poland \\ ${ }^{2}$ Chair and Department of Electroradiology, Poznan University of Medical Sciences, Poznan, Poland \\ ${ }^{3}$ Department of Chemotherapy, University Hospital of Lord's Transfiguration, Poznan, Poland \\ ${ }^{4}$ Department of Immunobiology, Poznan University of Medical Sciences, Poznan, Poland \\ ${ }^{5}$ Department of Oncology, Poznan University of Medical Sciences, Poznan, Poland \\ ${ }^{6}$ Department of Obstetrics and Gynecological Nursing, Faculty of Health Sciences, Medical University of Gdansk, Gdansk, Poland \\ ${ }^{7}$ INVICTA Fertility and Reproductive Center, Gdansk, Poland
}

Introduction. Breast cancer is the most common cancer in women - both in Poland and around the world. In terms of the mortality rate, it subsides brest cancer with lung cancer. In 2018, almost 2 million new cases were reported worldwide, and almost 44 million women have been diagnosed with breast cancer in the last 5 years.

Material. The aim of this paper is to present ways to improve the sexual well being of breast cancer patients.

Methods. Analysis of the literature by oncologists, gynecologists, and psychologists was used for theoretical discussion. Results. Sexuality is an extremely important part of every woman's life, including those suffering from breast cancer. Surgery of the breast, a symbol of a woman's sexuality, and the negative effects of cancer therapy can alter a woman's perception of her own body and lower her libido. Sexual therapy which should be based on multi-faceted activities, is an extremely important part of breast cancer treatment.

Conclusions. Therapeutic possibilities may be based on psychological and sexual therapies as well as pharmacological support (moisturizers, silicone lubricants, tampons inserted for several minutes with $4 \%$ vaginal lidocaine before intercourse, topical gels with estrogens, ospemifen, DHEA, testosterone).

Key words: sexuality well being, breast cancer, sexual satisfaction, sexual therapy, treatment, surgery

\section{Introduction}

Breast cancer is the most common cancer in women in Poland and around the world. In terms of the mortality rate, it subsides breast cancer with lung cancer. In 2018, almost 2 million new cases were reported worldwide, and almost 44 million women have been diagnosed with breast cancer in the last 5 years [1].

Early and modern diagnostics as well as effective treatments have improved the prognosis of women with breast cancer, i.e. increasing the time of total survival and improving the overall quality of life. The majority (about 70-80\%) of breast cancers show expression of hormonal (estrogen and/or progesterone) receptors, about 15-20\% are cancers showing an overexpression of the HER2 receptor or amplification of its gene, about $15 \%$ are the worst case prognoses - the so-called triple negative (without expression of hormonal receptors and an overexpression of the HER2 receptor). The expression of hormonal receptors has a predictive meaning, conditioning treatment that inhibits or significantly reduces the level of

\section{How to cite:}

Lachowicz M, Kufel-Grabowska J, Bartoszkiewicz M, Ramlau R, Łukaszuk K. Sexual well being of breast cancer patients. NOWOTWORY J Oncol 2021; 71 : 232-237.

This article is available in open access under Creative Common Attribution-Non-Commercial-No Derivatives 4.0 International (CC BY-NC-ND 4.0) license, allowing to download articles and share them with others as long as they credit the authors and the publisher, but without permission to change them in any way or use them commercially. 
sexual hormones. The treatment is usually applied by patients for 5-10 years.

Chemotherapy is used in most patients with triple negative and HER2-positive breast cancer, also occasionally in patients with hormone dependent breast cancer. Side effects of chemotherapy appear early in the course of treatment, such as nausea, vomiting, diarrhea, alopecia; some, after weeks, months or years of therapy - cardiomyopathy, myelodysplastic syndrome, or secondary malignancies.

Sexuality is an extremely important part of every woman's life, including those suffering from breast cancer. Surgery of the breast, a symbol of a woman's sexuality, and the negative effects of cancer treatment alter a woman's perception of her own body and lower her libido. The aim of this paper is to present ways to improve the sexual well being of breast cancer patients.

\section{Influence of systemic treatment on premature cessation of ovarian function}

Up to $1 / 3$ of women with recently diagnosed breast cancer, menstruate when the cancer is diagnosed. Chemotherapy causes premature cessation of ovarian function in about $30-40 \%$ of women under 40 years of age, and even in $90 \%$ of women over 40 years of age. In $90 \%$ of women under 35 years of age, menstruation only returns up to 2 years after the end of chemotherapy [2].

Approximately $64 \%$ of premenopausal women complain of hot flashes or night sweats during or after treatment, $42 \%$ of them have vaginal atrophy, $29 \%$ of them have osteoporosis, $28 \%$ even think about discontinuing breast cancer hormonal treatment because of the accompanying symptoms. Studies show that almost $1 / 3$ of these women have never been asked by their physician about the possible presence of vasomotor symptoms (hot flashes, sweats, increased blood pressure) [3].

The symptoms caused by menopause induced by cancer treatment are usually exacerbated. Physiological menopause is a long-term process, which is slow for many months, while menopause induced by cancer therapy often affects young patients experiencing a decrease in sexual hormone levels within a short time, even overnight. The changes in the body can be rapid and the symptoms rather troublesome.

\section{Influence of systemic treatment on fertility}

Extra attention is also being paid to reproductive issues. Women want to be mothers and enjoy motherhood, despite their cancer. Current anticancer treatments have a significant impact on a woman's reproductive abilities.

Over the years, women have been deciding to have offspring later. Now the average age of a European woman at the birth of her first child is 39 years. Subsequently, a breast cancer diagnosis can appear before or during a woman's procreation plans. Systemic treatment can not precipitate the cessation of ovarian function, but also postpone the moment when it is possible and safe to become pregnant. Pregnancy after breast cancer treatment is possible and safe.
Every woman of childbearing age should be informed about the side effects of treatment as well as the possibility of using fertility preservation techniques; they can also be referred to a reproductive medicine specialist before starting cancer treatment. The most commonly used techniques with proven effectiveness include: the collection and freezing of oocytes or embryos. The choice of an appropriate method depends on age, a woman's ovarian reserve, and the planned oncological treatment.

It is worth taking care to maintain fertility before cancer treatment, which will make a woman's life more comfortable. Sex need not only be a way to get pregnant, but can also be a source of pleasure.

\section{Reproduction after breast cancer}

Indeed, for many young women, the possibility of having children after completing cancer treatment is significant. Of course, a decision about pregnancy may be challenging and problematic due to prevailing myths and distortions regarding the safety of the future mother's pregnancy, the impact of chemotherapy on the fetus and the child, and breastfeeding issues.

A breast cancer diagnosis is usually accompanied by shock, fear, disbelief, anxiety, and high-stress levels. Hence, patients accumulate all their thoughts around treatment, rejecting decisions related to functioning, fertility, and motherhood after treatment. After undergoing anticancer treatment, the possibility of becoming pregnant may be significantly limited or completely unavailable. This is caused by the toxic effects of drugs on the gonads [4-6].

Young female patients, premenopausal, who became sterile due to anticancer treatment, may experience many psychological difficulties, including depression. In addition, some patients may experience intense fear and the fear of a recurrence of the disease and related problems or e.g. the inability to raise a child. This fear can be so overwhelming that some women stop trying to get pregnant. Therefore, it is worth emphasizing the role of psychological counseling therapy, and the benefit of support from a psycho-oncologist or sexologist who can help women and their partners make the right decisions, and choose the best solutions during diagnosis and post-treatment [7-9].

Unfortunately, it still happens all too often that physicians do not sufficiently and adequately inform patients at the time of diagnosis about the possibility of preserving fertility. Such inconsistent and hard communication with the patient causes frustration and anger and is associated with increased stress. Therefore, it should be remembered how vital motherhood is, for it can be a significant element in aiding women's psychological rehabilitation after breast cancer treatment.

\section{The influence of surgical treatment on the perception of one's body}

Breast cancer and the methods involved in its treatment have a very important impact, not only on somatic health or the 
patients' quality of life, but above all on the extremely important psychological and sexual sphere, as well as on the attitude to one's body. This is particularly evident in the case of a one-sided or two-sided mastectomy, which changes the way patients perceive, feel, and experience emotional, social, and family life. Surgical treatment of cancer causes a woman to start perceiving their body differently. In addition, the sense of aesthetics deteriorates and there is increased restraint of women body, which undoubtedly has a significant impact on one's awareness of beauty and self-esteem, causing a disparity between the idealized, sexually attractive image of a woman ubiquitous in popular media, and the body of a cancer patient after treatment [10-12].

The process of cancer treatment has a significant impact on the patient's quality of life, as well as on the satisfaction level of sexual well being. Unfortunately, the sexual aspect is still often neglected, without due diligence. Sexuality is one of the important components of general health and quality of life.

The Declaration of Human Sexual Rights established by the World Sexual Health Organization (2014) [13] assumes that: "Sexuality is a key aspect of a person's life throughout its entire duration and includes gender, roles and sexual identities (socio-cultural gender-related), sexual orientation, eroticism, pleasure, intimacy and reproduction. Sexuality is experienced and expressed in the form of thoughts, fantasies, desires, beliefs, attitudes, values, behaviors, practices, roles and relationships. Sexuality can include all of the above, but not all of its dimensions must be experienced or expressed. Human sexuality is influenced by complex biological, psychological, social, economic, political, cultural, legal, historical, religious and spiritual factors".

Of course, the psychological aspect, emotional sphere, or sense of attraction for the patient's partner should not be omitted here; this undoubtedly affects the quality of one's sexual life, as it is associated with self-esteem, a sense of self-respect, and an acceptance of the body that was changed by the cancer. According to Zdończyk S.A. [14], women after cancer surgery show a worryingly low self-esteem as sexual partners. Therefore, it seems appropriate to rationally approach this type of disorder.

The psychophysical condition and psychological well-being of a breast cancer patient are often very unsatisfactory. Their reduced level of self-esteem and the presence of the disease are often the main factors that cause sexual disorders. The patient's approach to their own body, sexuality, well-being, sense of attraction, and relationship with their partner are all extremely important. If before surgery, the patient had a low opinion of their attractiveness, and exhibited low self-esteem, these feelings will be all the more exacerbated after treatment. Many women struggle with the so-called half-woman complex - the loss of one breast, the resulting asymmetry of the body, scarring; these are all reasons for a serious reduction in the level of one's visual self confidence regarding appearance [15].
In addition to the patient's lack of self confidence, their mood or depression, which may develop during the cancer and cancer treatment process, is also worth noting. In such a case, the therapy to combat depression should be undertaken with the appropriate diagnosis. The socio-cultural standards of beauty, ubiquitous sexuality, and the perfect ideal of woman's body present in the mass media are also important factors that may speed up the development of these disorders.

Patients often feel that sex is unnatural, forced, and often involves internal compulsion. The woman feels guilty of her indisposition, her attitude begins to become more restrictive, until she finally gives up on sexual activity completely.

\section{Sexual satisfaction}

It is safe to say that sexual satisfaction is largely related to the quality of relationship in which the woman realizes herself sexually. Furthermore, the satisfaction that results from sexual intercourse should be considered a vital element of any successful original meaning [16]. There is no doubt that sexual satisfaction is a very important element of sexual activity. It is recognized as an important indicator of health in the sexual sphere, as well as an exponent of well being and quality of life; a satisfying sex life determines both the quality and endurance of a partnership $[17,18]$

The frequency of initiated behaviors and sexual activities is associated with sexual satisfaction and, consequently, the satisfaction of a partnership or marriage $[19,20]$. The forms of breast cancer treatment, and the methods used are often very aggressive, subsequently causing a number of inconveniences and side effects. These include, among others, sexual disorders, which significantly reduce the state of one's sexual health. The patient feels a recurring problem of a sexual nature, and discomfort and dissatisfaction with sexual activity [21]. There are four basic categories of sexual disorders in women:

- reduced desire - a reduction or loss of interest in sexual issues, images related to sexual activity, a reduction of feelings of desire and thoughts regarding sex-related matters,

- sexual arousal disorders - the genital response is insufficient in terms of lack of vaginal lubrication and inadequate swelling of the lips of the vulva,

- orgasm disorders - associated with an orgasm dysfunction, its delay or complete absence,

- dyspareunia - permanent or recurring pain of the genitals occurring during the course of penis penetration into the vagina throughout intercourse (including during a gynecological examination)

Sexual dysfunctions resulting from cancer treatment may have serious consequences and significantly affect the patient's quality of life, their relationship with a partner, psychological difficulties. They may cause the patient to avoid sexual intercourse, in addition, there may be unpleasant associations with sexual activity, or shifting the blame to the partner, which, 
in turn may lead to a complete breakdown of their intimate relationship.

It should be clearly emphasized that patients treated for breast cancer experience a decrease in physical activity and satisfaction with their sexual life. In addition, desire disorders, orgasm problems, breast sensation disorders, vulvovaginal atrophy, menopausal symptoms appear (hot flashes, sweating, fatigue, joint and muscle pains, irregular menstruation, irritability, intimate infections, weight loss), or lubrication disorders $[13,22]$.

Pain associated with sexual activity results in a negative attitude towards sexuality, and thus increases the impairment of sexual function. Patients with dyspareunia are accompanied by reduced frequency of sexual intercourse and are less enthusiastic about initiating this type of behavior. They also have a reduced desire level, excitement is diminished, with less intense feelings of orgasm during intercourse [23].

\section{Sexual therapy}

The issue of women's sexuality after breast cancer treatment still seems taboo. It is possible to observe an increased number of publications devoted to this subject, but this is still insufficient. Patients, their families, and even medical staff often feel too much embarrassment and shame to report problems, with regards to the prospect of discussing the diagnosis and analyzing the sexual concerns that arise. There is still an inner conviction that compared to the grave severity of cancer, which is a real threat to life, the subject of possible sexual dysfunction is trivialized.

Sexual therapy, which should be based on multi-faceted activities, is an extremely important process that has a key role:

- $\quad$ first stage - conversation with the patient about the problem in the sexual sphere related to the disease or its treatment,

- second stage - gathering as much knowledge as possible about the problem, its origin, details and aspects of the patient's sexual life by the physician,

- third stage - detailed suggestions, i.e. conversation/consultation with specialists in the field of sexology, psychology or oncology based on an individual approach to the problem,

- fourth stage - intensive care for patients who require it or who have been recommended, which may include psychotherapy, pharmacological therapy or surgery [24].

\section{Pharmacological treatment}

Problems during intercourse can be permanent or recurring. They may appear during penetration or intercourse. They may even arise earlier as a fear of penetration or intercourse, and the associated tension and tightening of the pelvic floor muscles.

Treatment must first start with awareness and discussion of the problem. If there is openness in the relationship, the partner should also be involved in the treatment. The patient should be listened to but also be aware that the range of standards and expectations of sexuality are very different, not only between people, but even during the individual process of puberty, maturity, and aging. The disease, and especially the treatment of the disease, will have a significant impact on the leap in sexual stimulation and excitement curve that is appropriate for the patient. Expectations about the necessity of intercourse may also be relative. However, if penetration is expected, additional measures to increase comfort and facilitate sexual activity are desirable. The definition of expected sexual satisfaction is a reference point for proposing further treatment. Based on the diagnosed problems and expectations, individualized treatment should be chosen.

Therapeutic possibilities may be based on psychological and sexual therapies as well as pharmacological support. Treatment of physical problems during intercourse can be based on an algorithm of gradually increasing the invasiveness of treatment, depending on the difficulty of obtaining the expected effect [25]. In the first stage, moisturizers are proposed, while opinions about lubricants are more ambiguous. Using the former in doses larger than standard, achieves good vaginal lubrication and a transient positive effect during intercourse [26]. If a positive effect is obtained, its stability should be verified and the treatment in case of its loss should be modified. In case of further problems with the use of maximum amounts of silicone lubricants, it is proposed to use tampons for several minutes before intercourse with $4 \%$ vaginal lidocaine.

In the next stage, the use of topical gels with estrogens in minimal doses may be considered. As both opinions and published data on the potential risk of steroid use in patients treated for breast cancer are divided [27], a decision on hormone treatment should be made together with the patient. Approximately 30-50\% of women opt for estrogen treatment under medical supervision [28]. Some of them would also accept an increase of $1 / 3$ of the risk of relapse, if the treatment resulted in cessation of symptoms [29]. It is assumed that doubling the level of estradiol in the blood increases the risk of relapse by about $1 / 3$ [30]. Therefore, estradiol levels should oscillate within this range.

There is no direct correlation between serum estrogen levels and the resolution of symptoms associated with vaginal atrophy, thus the dose should be adjusted to the quality of vaginal mucosa and function required. The period of epithelial regeneration under the influence of hormones takes about 4 weeks. During this period, estrogens more easily penetrate the atrophic vaginal mucosa into the bloodstream. Therefore, minimum doses should be used to rebuild the vaginal epithelium at the expense of prolonging its regeneration time.

It is also worth noting that most breast cancer patients with hormone receptor expressions use tamoxifen or aromatase inhibitor based therapy for 5-10 years. Tamoxifen is an estrogen receptor modulator (selective estrogen receptor modulator - SERD), it stimulates or blocks its activity, depen- 
ding on its location in the body. Aromatase inhibitors inhibit the aromatization of androgens to estrogen primarily in the fat tissue, inhibiting their production, but without affecting the effects of estrogen on the receptor. Due to their mechanism of action (aromatase inhibitors), it seems that for those patients who use tamoxifen, the vaginal estrogen effect will be mainly limited to topical effects.

Among the possible estrogens to use, the selective estrogen receptor modulator ospemifen should be mentioned. It is recommended in post-menopausal women with severe symptoms: dryness and vaginal atrophy. Due to its beneficial effect profile, it is not contraindicated in women with breast cancer after the completion of adjuvant therapy [31].

The use of DHEA is also considered both orally and vaginally. In both cases, this treatment seems to reduce the symptoms of vaginal atrophy and improve sexual function without increasing estrogen levels above the expected levels [32]. The use of testosterone is more controversial. It improves satisfaction from intercourse, increases libido, improves mood and general well-being, but there are no clear data on the safety of its use in women who are being treated for breast cancer [33].

It is extremely important to educate patients to be open to conversations related to sexuality in order for them to enjoy life to the fullest, despite the disease, and to feel satisfaction and contentment. It is worthwhile informing patients about available methods and strategies for dealing with sexual dysfunction. Providing basic knowledge on how to properly lubricate vaginal walls before sexual intercourse with the use of water or silicone based lubricants, as well as the systematic use of vaginal globules or gel applications with hyaluronic acid can significantly contribute to improving the sex life of women.

It is also worth referring the patient to a urogynelogical physiotherapist, in order to stimulate the blood supply to the genitals through the use of appropriate relaxation exercises for vaginal muscles.

\section{Conclusions}

Sexual activity and performance are extremely important in human life. Treatment of breast cancer certainly has a negative impact on a patient's emotional state, their mental state, but also on the sexual satisfaction and intimate relations with a partner [34]. Patients treated with breast-conserving therapy are still relatively few in Poland [35]. Proper breast oncology surveillance during pregnancy, using safe and inexpensive methods including ultrasonography and biopsy of suspicious masses, can ensure the prevention of cancer development and progression [36]. The stage of the disease at diagnosis is also a major prognostic factor in pregnancy-related cervical cancer [37].

Sexual dysfunctions may also occur after treatment is completed, which is undoubtedly associated with a decrease in satisfaction and contentment resulting from a decrease in the quality of intimate relationships. Unfortunately, in most cases, women are not informed about the possibilities of dealing with this problem. The diagnosis and consequences of treatment affect intimate relationships [38]. Relationship with one's partner is a very important factor that determines the psychosocial health of patients.

Unfortunately, women's knowledge of changes in their body during the disease and their knowledge of solutions to sexual disorders is still inadequate. Patients are ashamed to talk to an oncologist about sexuality or dysfunctions that have arisen as a result of oncological treatment. Zdończyk (2015) points out that there is still a big taboo evident; a barrier is created by shame, lack of trust from the patient, ignorance of proper terminology, and a basic lack of openness or empathy from the physician. All this is further exacerbated by the lack of sufficient time and knowledge of physicians or other health care representatives

It is worth noting that the subject of sexuality of patients treated for breast cancer is becoming more discussed. This paper does not exhaust the entire subject, and the area of issues could be more detailed with regard to the psychophysical difficulties associated with the disease, as well as the various approaches to the subject of the disease and the disorders resulting from it, along with the communication problems between the patient and the health service.

\section{Conflict of interest: none declared}

\section{Mikołaj Bartoszkiewicz}

University of Medical Sciences

Department of Immunobiology

ul. Rokietnicka 8

60-806 Poznań, Poland

e-mail:m.bartoszkiewicz@ump.edu.pl

Received: 11 Mar 2021

Accepted: 30 Apr 2021

\section{References}

1. Bray F, Ferlay J, Soerjomataram I, et al. Global cancer statistics 2018: GLOBOCAN estimates of incidence and mortality worldwide for 36 cancers in 185 countries. CA Cancer J Clin. 2018; 68(6): 394-424, doi: 10.3322/caac.21492, indexed in Pubmed: 30207593.

2. Oktay $K$, Harvey BE, Partridge AH, et al. Fertility Preservation in Patients With Cancer: ASCO Clinical Practice Guideline Update. J Clin Oncol. 2018; 36(19): 1994-2001, doi: 10.1200/JCO.2018.78.1914, indexed in Pubmed: 29620997.

3. Fiorentino $L$, Rissling $M$, Liu $L$, et al. The Symptom Cluster of Sleep, Fatigue and Depressive Symptoms in Breast Cancer Patients: Severity of the Problem and Treatment Options. Drug Discov Today Dis Models. 2011; 8(4): 167-173, doi: 10.1016/j.ddmod.2011.05.001, indexed in Pubmed: 22140397.

4. Henry NL, Xia R, Schott AF, et al. Prediction of postchemotherapy ovarian function using markers of ovarian reserve. Oncologist. 2014; 19(1): 68-74, doi: 10.1634/theoncologist.2013-0145, indexed in Pubmed: 24319018.

5. Rossi L, Pagani O. Impact of Breast Cancer Treatment on Fertility. Breast Cancer, Fertility Preservation and Reproduction. 2015: 29-43, doi: 10.1007/978-3-319-17278-1_3.

6. Meirow D, Schiff E. Appraisal of chemotherapy effects on reproductive outcome according to animal studies and clinical data. J Natl Cancer Inst Monogr. 2005(34): 21-25, doi: 10.1093/jncimonographs/lgi025, indexed in Pubmed: 15784816. 
7. Carneiro MM, Cota AM, Amaral MC, et al. Motherhood after breast cancer: can we balance fertility preservation and cancer treatment? A narrative review of the literature. JBRA Assist Reprod. 2018; 22(3): 244252, doi: 10.5935/1518-0557.20180032, indexed in Pubmed: 29932615.

8. Knabben L, Mueller MD. Breast cancer and pregnancy. Horm Mol Biol Clin Investig. 2017; 32(1), doi: 10.1515/hmbci-2017-0026, indexed in Pubmed: 28850544.

9. Christian N, Gemignani ML. Issues with Fertility in Young Women with Breast Cancer. Curr Oncol Rep. 2019; 21(7): 58, doi: 10.1007/s11912019-0812-4, indexed in Pubmed: 31098718.

10. Słowik AJ, Jabłoński MJ, Michałowska-Kaczmarczyk AM, et al. Evaluation of quality of life in women with breast cancer, with particular emphasis on sexual satisfaction, future perspectives and body image, depending on the method of surgery. Psychiatr Pol. 2017; 51(5): 871-888, doi: 10.12740/PP/OnlineFirst/63787, indexed in Pubmed: 29289967.

11. Montazeri A. Health-related quality of life in breast cancer patients: a bibliographic review of the literature from 1974 to 2007. J Exp Clin Cancer Res. 2008; 27: 32, doi: 10.1186/1756-9966-27-32, indexed in Pubmed: 18759983.

12. Howard-Anderson J, Ganz PA, Bower JE, et al. Quality of life, fertility concerns, and behavioral health outcomes in younger breast cancer survivors: a systematic review. J Natl Cancer Inst. 2012; 104(5): 386-405, doi: 10.1093/jnci/djr541, indexed in Pubmed: 22271773.

13. World Association for Sexual Health. Declaration of Sexual Rights. https://worldsexualhealth.net/wp-content/uploads/2013/08/Declaration-of-Sexual-Rights-2014-plain-text.pdf (15.01.2021).

14. Zdończyk SA. [The effect of selected socio-medical factors on quality of life and psychosexual functioning in women after surgical treatment of breast cancer]. Pomeranian J Life Sci. 2015; 61(2): 199-206, indexed in Pubmed: 27141607.

15. Jarząbek-Bielecka G. An outline of sexual problems in patients with breast cancer. Curr Gynecol Oncol. 2018; 16(1): 50-56, doi: 10.15557/ cgo.2018.0006.

16. Specjalski R, et al. Gren' M, Bulińska K, Sexual satisfaction and relationship satisfaction in homosexual men. Seksuologia Pol. 2014; 12(2): 64-69.

17. Janowski K, Czyżowska A. Psychometric properties of the Polish version of the sexual life satisfaction scale for women. Przegl Seks. 2013; 9: 36-40.

18. Lew-Starowicz Z, Skrzypulec V. Fundamentals of sexology. PZWL Wydawnictwo Lekarskie, Warszawa 2010.

19. Yucel D, Gassanov M. Exploring actor and partner correlates of sexual satisfaction among married couples. Soc Sci Res. 2010; 39(5): 725-738, doi: 10.1016/j.ssresearch.2009.09.002.

20. Izdebski Z. Sex in Polish. Sexual behavior as an element of Poles'lifestyle. Wydawnictwo MUZA S.A., Warszawa 2003.

21. Ratner ES, Erekson EA, Minkin MJ, et al. Sexual satisfaction in the elderly female population: A special focus on women with gynecologic pathology. Maturitas. 2011; 70(3): 210-215, doi: 10.1016/j.maturitas.2011.07.015, indexed in Pubmed: 21943557.

22. Ussher J, Perz J, Gilbert E. Changes to Sexual Well-Being and Intimacy After Breast Cancer. Cancer Nursing. 2012; 35(6): 456-465, doi: 10.1097/ ncc.0b013e3182395401.

23. Heim LJ. Evaluation and differential diagnosis of dyspareunia. Am Fam Physician. 2001; 63(8): 1535-1544, indexed in Pubmed: 11327429.
24. Lindert O, Skrzypulec-Plinta V, Plinta R, et al. Use of hormone therapy in gynaecological oncology and therapy of breast cancer. Menopausal Rev. 2010; 14(2): 78-83.

25. Carter J, Goldfrank D, Schover LR. Simple strategies for vaginal health promotion in cancer survivors. J Sex Med. 2011; 8(2): 549-559, doi: 10.1111/j.1743-6109.2010.01988.x, indexed in Pubmed: 20722792.

26. Biglia N, Peano E, Sgandurra P, et al. Low-dose vaginal estrogens or vaginal moisturizer in breast cancer survivors with urogenital atrophy: a preliminary study. Gynecol Endocrinol. 2010; 26(6): 404-412, doi: 10.3109/09513591003632258, indexed in Pubmed: 20196634.

27. Rossouw JE, Anderson GL, Prentice RL, et al. Writing Group for the Women's Health Initiative Investigators. Risks and benefits of estrogen plus progestin in healthy postmenopausal women: principal results From the Women's Health Initiative randomized controlled trial. JAMA. 2002; 288(3): 321-333, doi: 10.1001/jama.288.3.321, indexed in Pubmed: 12117397.

28. Marsden Jo, Whitehead $M, A^{\prime}$ Hern R, et al. Are randomized trials of hormone replacement therapy in symptomatic women with breast cancer feasible? Fertil Steril. 2000; 73(2): 292-299, doi: 10.1016/s0015-0282(99)00510-5.

29. Ganz PA, Greendale G, Kahn B, et al. Are breast cancer survivors willing to take hormone replacement therapy (HRT) (abstract A102). Proceedings of the Annual Meeting of Society Clinical Oncology. 1996; 15.

30. Key T, Appleby P, Barnes I, et al. Endogenous Hormones and Breast Cancer Collaborative Group. Endogenous sex hormones and breast cancer in postmenopausal women: reanalysis of nine prospective studies. J NatI Cancer Inst. 2002; 94(8): 606-616, doi: 10.1093/jnci/94.8.606, indexed in Pubmed: 11959894.

31. Portman DJ, Bachmann GA, Simon JA. Ospemifene, a novel selective estrogen receptor modulator for treat- ing dyspareunia associated with postmenopausal vul- var and vaginal atrophy. Menopause. 2013; 20(6): 623-630.

32. Labrie F, Archer D, Bouchard C, et al. Serum steroid levels during 12-week intravaginal dehydroepiandrosterone administration. Menopause. 2009; 16(5): 897-906, doi: 10.1097/gme.0b013e31819e8930, indexed in Pubmed: 19436226.

33. Dizon DS, Suzin D, Mcllvenna S. Sexual health as a survivorship issue for female cancer survivors. Oncologist. 2014; 19(2): 202-210, doi: 10.1634/ theoncologist.2013-0302, indexed in Pubmed: 24396051.

34. Fobair P, Spiegel D. Concerns about sexuality after breast cancer. Cancer J. 2009; 15(1): 19-26, doi: 10.1097/PPO.0b013e31819587bb, indexed in Pubmed: 19197169.

35. Kufel-Grabowska J, Radecka B, Streb J, et al. Breast-conserving surgeries in HER-positive breast cancer patients are performed too rarely in Poland. NOWOTWORY J Oncol. 2020; 70(6): 225-229, doi: 10.5603/njo.2020.0047.

36. Kalantarova A, Zembol N, Kufel-Grabowska J. Pregnancy-associated breast cancer as a screening and diagnostic challenge: a case report. NOWOTWORY J Oncol. 2021; 71(3): 162-164, doi: 10.5603/njo.a2021.0017.

37. Danielska J, Moszyńska-Zielińska M, Gottwald L, et al. Pregnancy-related cervical cancer in the material of the Regional Cancer Centre, Łódź, between 2011 and 2014. Nowotwory. Journal of Oncology. 2017; 66(5): 359-366, doi: 10.5603/njo.2016.0065.

38. Rottmann N, Gilså Hansen D, dePont Christensen R, et al. Satisfaction with sex life in sexually active heterosexual couples dealing with breast cancer: a nationwide longitudinal study. Acta Oncol. 2017; 56(2):212-219, doi: 10.1080/0284186X.2016.1266086, indexed in Pubmed: 28080186. 